\title{
Dangerous crossing: demographic and clinical features of rescued sea migrants seen in 2014 at an outpatient clinic at Augusta Harbor, Italy
}

Alessia Trovato ${ }^{1 *}$, Anthony Reid ${ }^{2}$, Kudakwashe C. Takarinda ${ }^{3}$, Chiara Montaldo ${ }^{1}$, Tom Decroo ${ }^{4}$, Philip Owiti ${ }^{5}$, Francesco Bongiorno ${ }^{6}$ and Stefano Di Carlo ${ }^{1}$

\begin{abstract}
Background: In recent years Europe has received an increasing influx of migrants, many of whom risked their lives crossing the Mediterranean Sea. In October 2013, Italy launched a search and rescue operation at sea in response to migrant deaths during the sea crossing. In August 2014, Médecins sans Frontières and the local Ministry of Health established an outpatient clinic at Augusta harbor, in Sicily, which received $26 \%$ of total sea migrants arrived in Italy in 2014, to provide immediate medical assessment and care.

Methods: This is a descriptive study of demographic and clinical data of sea migrants seen at the port clinic in Augusta from August to December 2014. We compared migrants from Near Eastern, war-torn regions (Group 1) and the others, mostly African (Group 2), as there were significant differences in terms of demographic and morbidity profiles.

Results: There were 2593 migrants consulting the clinic (17\% af all rescued migrants) with $5 \%$ being referred to hospital. Most were young males. The overall burden of vulnerability (pregnant women, children $\leq 5$ years, unaccompanied minors, single parents with children of minor age, disabled and elderly persons) was $24 \%$. There were more small children, pregnant women, elderly, disabled, and persons with chronic diseases in Group 1, as compared to Group 2. Group 2 had more unaccompanied minors. Morbitidies in common were respiratory, dermatological, trauma-related and gastrointestinal conditions. However, acute and chronic cardiovascular disease, as well as diabetes, were more frequent in Group 1; chronic diseases affected $19 \%$ of this group. Group 2 had more patients with skin diseases. Most migrants attributed their presenting symptoms to the perils of their journey. No risks for public health were detected.

Conclusion: Among sea migrants, we identified two groups with different demographic and clinical characteristics, as well as vulnerability patterns. Overall morbidity suggested that the dangerous journey affected migrants' health. Medical activities at reception sites should include screening for vulnerability and chronic disease management. Ensuring medical care to migrants on arrival can address European humanitarian obligations and provide support to local medical facilities.
\end{abstract}

Keywords: Sea Migrants, Health status, Hospital referrals, Vulnerability, SORT IT, Operational Research

\footnotetext{
* Correspondence: alessia.trovato@posteo.de

${ }^{1}$ Medici Senza Frontiere Italia, Via Magenta 5, Roma 00185, Italy

Full list of author information is available at the end of the article
} 


\section{Background}

Over the past 4 years, Europe has experienced an increasing influx of migrants crossing the Mediterranean Sea seeking humanitarian protection and/or improved living conditions $[1,2]$. Most are fleeing war, persecution or extreme poverty [3].

In this study we define "migrants" as persons moving from one place to another, regardless of their legal status or reasons for travelling. All migrants in this study were rescued at sea, therefore we refer to them as sea migrants.

The number of sea migrants has escalated substantially since 2011 (62,500 in 2011, 43,000 in 2013, 170,000 in 2014) following the Syrian war, the rise of the Islamic State, as well as the political crisis in Libya. In 2015 about a million of them have reached Europe [1, 2].

Before 2011, the vast majority of sea migrants came from Africa (North and West Africa, and Horn of Africa), but recently, a significantly higher proportion of them has come from the Near East and Asia (Syria, Iraq, Afghanistan, Pakistan and Bangladesh) and includes migrants of minor age [1, 2, 4]. Furthermore, migration routes have been shifting, with Southern Italy being the major landing point up to 2014 and Greece representing the most crossed European border in 2015 [1, 2].

The sea journey, as well as the land crossing, are extremely dangerous and expose the migrants to risks that threaten their health $[3,5,6]$. Between October 2013 and November 2014 the Italian government implemented the search and rescue operation called Mare Nostrum (OMN) to address the increase in deaths of migrants during their sea crossing $[3,7]$. The two main landing sites for rescued migrants were Augusta (Province of Siracusa) and Pozzallo (Ragusa), in Sicily [8, 9]. In 14 months, OMN rescued 160,000 sea migrants [10].

The extraordinary wave of sea migration in 2014 represented a challenge for Italian authorities in terms of reception capacity and providing adequate medical assistance. In addition, the Ebola epidemics in West Africa aroused fear of importation of communicable diseases that could represent a public health burden in Italy and the rest of Europe [11]. Therefore, following an official agreement with the local branch of the Ministry of Health $(\mathrm{MoH})$, the medical humanitarian organization Médecins Sans Frontières (MSF) supported medical care for rescued migrants at both landing sites. The collaboration project in Augusta, the busiest port, started on August 1 and ended on December 31, 2014, when all activities were handed over to $\mathrm{MoH}$.

There is some literature regarding sea migrants. Three previous studies analyzed medical activities in Malta in 2010-2011, in Lampedusa in 2010 as well as in 139 immigration centers operating in 13 Italian regions from May 2011 to June 2013. These studies showed that migrants were usually young men from African countries [12-14]. Although most were healthy or presented with minor health conditions, the main diseases observed were dermatological, respiratory and gastrointestinal. Furthermore, a significant part of their morbidity was related to the migration experience and/or the adjustment to the new environment in Italy. No major risks to public health were observed. Three previous studies focused on reasons for referral of migrants to hospitals in Lampedusa and Palermo [15-17].

In addition, studies in countries receiving a significant influx of migrants, including Italy, Spain, Germany and Greece, sought to describe health needs of immigrants as well as factors impairing their utilization of health care services [17-20]. However, these studies focused on the health status of migrants already settled in European countries.

What is lacking is accurate and up-to-date information regarding the burden of illnesses of migrants on their arrival in order to provide accessible and adequate medical care. As well, the changing profile of migrants has not been documented. This information is especially relevant for countries receiving the majority of them such as Greece, Italy and Germany during 2015. It is also important to document the health status of recently arrived migrants to properly evaluate their potential impact on European public health and health care systems.

The aim of this study was to define the demographic and clinical features, as well as referral patterns of newly arrived sea migrants seen at a MSF-MoH outpatient clinic at Augusta harbor from August 1-December 31, 2014. In addition, we compared migrants from Near Eastern war-torn regions (Syrians, Iraqis and Palestinians) versus those of all other nationalities (mostly from Africa), as there appeared to be substantial differences in terms of demographic and clinical characteristics.

\section{Methods \\ Design}

This is a descriptive study of routinely-collected project data.

\section{Setting \\ General setting}

In 2014 an unprecedented number of sea migrants arrived in Italy, with Sicily being the final destination for over $70 \%$ of them $[8,9]$. The death toll related to sea migration became a humanitarian challenge for the European Union [3, 5, 6]. In response, OMN was established by the Italian Government and Navy in October 2013 to actively search for and rescue migrants at sea [3, 7]. Rescue operations could involve several migrant boats. The largest military vessels offered medical first aid for rescued migrants and physicians of the $\mathrm{MoH}$ 
Prevention Department examined all migrants for communicable diseases on board before disembarkment (Fig. 1). Most rescued migrants were brought to Augusta (Province of Siracusa) and Pozzallo (Ragusa) as they are two large harbors on the eastern and southern coast of Sicily with easily accessible reception facilities for migrants $[8,9]$.

\section{Specific Setting}

Augusta, the busiest reception port, is located on the eastern Sicilian coast. Out of the 170,000 migrants who reached Italy by sea in 2014, 120,200 (71 \%) landed in Sicily. Of these, 44,300 landed in Augusta (26\% of total migrants arriving in Italy) [8].

The MSF-MoH clinic was set up at Augusta harbor to provide medical care for migrants on arrival as well as to reduce overcrowding of local health facilities. It was located in the port camp and included tents for clinical evaluation and registration, observation and treatment (separated by gender), as well as a container used as a pharmacy.

\section{Migrant flow}

The migrant flow at Augusta port is shown in Fig. 1. They underwent one or two medical triages by $\mathrm{MoH}$ and Italian Red Cross (CRI): the first, on board the rescue vessel, aimed at identifying communicable diseases of public health significance; the second, on the dock, according to the CESIRA system, to briefly assess migrants' health and select cases requiring hospital referral or treatment at the MSF-MoH clinic [21].
After triage, migrants reached the port camp where they were identified by Immigration Police, and subsequently transferred to temporary accommodation facilities outside the port. MSF-MoH medical activities were confined to the time from disembarkment to transfer out.

During this time, migrants with health complaints visited the clinic after being informed about services through promotional activities by MSF staff, NGOs or through other migrants. At times of lower workload, MSF engaged in active case-finding for migrants with medical issues and/or vulnerabilities.

\section{Clinical activities}

MSF staff, supported by $\mathrm{MoH}$ personnel, included two physicians, two nurses, and two to three cultural mediators. They spoke English, French, Arabic, Tigrinya, and Amharic, the most frequently spoken languages among the migrants.

The main MSF-MoH activities included medical consultations, clinical observation and treatment, organization of hospital referrals, follow-up of referred patients, communication with local $\mathrm{MoH}$ actors and NGOs, and pharmacy management. For each patient, a maximum of two presenting conditions were recorded. They were categorized by body systems or organs. We listed separately: trauma, the request for medical check-up and fever without infection signs, as they represented a significant burden of consultations. All presenting conditions not meeting the above definitions were categorized as "others".

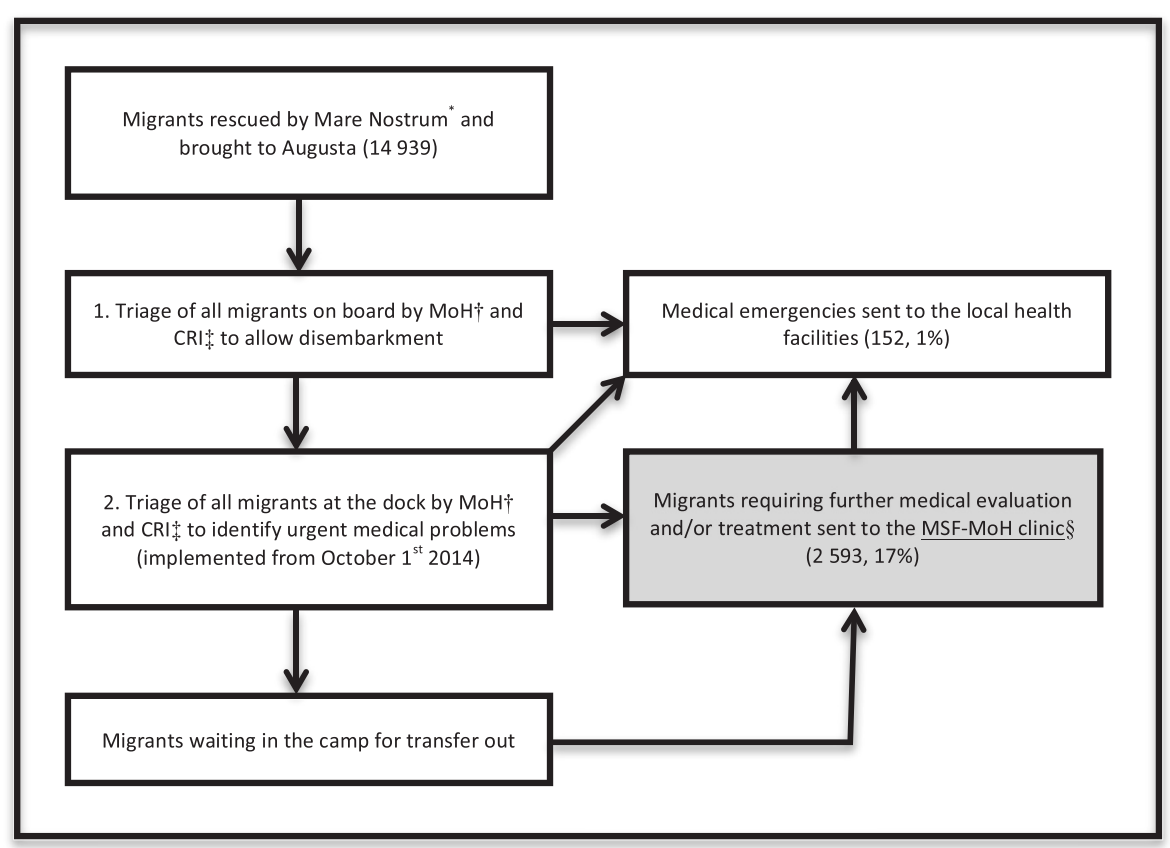

Fig. 1 Flow of rescued sea migrants upon arrival at Augusta harbor (Italy) from Aug 1-Dec 31, 2014. *Search and rescue operation at sea launched by Italian Authorities in October 2013. †MoH - Ministry of Health. ¥CRI - Italian Red Cross. §MSF - Médecins sans frontières 
Diagnoses were made by physicians based on clinical assessment and simple tests (body temperature, blood pressure, blood sugar, urine dipstick, malaria rapid test, pregnancy test). Numbers and proportions for single diseases were not available since final diagnoses were not systematically recorded in the register. Due to time and context constrains we were unable to systematically screen for mental health conditions.

Screening for tuberculosis was based on patient interviews and physical examinations. Clinical suspects were sent to health facilities for testing. All treatments were provided according to national and MSF guidelines [22]. Due to potential contagiousness, patients with scabies were treated on site and recorded in a separate register.

A "health pass" containing demographic and clinical information was given to each patient with any clinical condition requiring medical follow-up, including chronic diseases, ongoing treatments, pregnant women, and children with incomplete or unknown vaccination status.

Criteria for referral to local health facilities were based on severity of illness, presence of vulnerability, and the need for advanced diagnostics and/or specific treatment.

\section{Study population}

This study included all patients seen at the MSF-MoH clinic from August 1-December 31, 2014. Patients were sent to the clinic upon triage at the dock or consulted the clinic spontaneously, or upon active case-finding. Whenever possible, MSF staff tried to identify and examine patients with vulnerabilities (defined as pregnant women, children $\leq 5$ years, unaccompanied minors, single parents with children of minor age, disabled and elderly persons). Age groups and vulnerabilities were determined according to their clinical relevance in the specific setting and based on MSF conventions.

\section{Data sources, data collection and variables}

Information about each landing, including total number of migrants, number of adult males and females, number of accompanied and unaccompanied minors, and nationality was provided by Italian Authorities (Immigration Police). Information about the origin of the boat(s), the number of days spent at sea, possible adverse events during the sea crossing, such as shipwreck, was obtained directly from the migrants.

Patient data were collected by MSF staff during each consultation as well as through follow-up of hospitalreferred cases, and entered manually onto paper registers, followed by single-entry into an Excel database (Microsoft Excel, 2011). All fields in the database were validated through crosschecking with paper data.

\section{Analysis and statistics}

Categorical variables were summarized using frequencies and proportions; medians and interquartile range were reported for skewed continuous variables. Comparisons of proportions were done using the Chi-square test where appropriate, or alternatively the Fisher's Exact test, with levels of significance set at $5 \%$. Only significant $p$-values $(P<0.05)$ were recorded in the tables. Sample size calculation was not required as all patients were included.

\section{Ethics approval and consent to participate}

Consent for utilization of data for analysis and publication was obtained from local $\mathrm{MoH}$ and Italian MSF Coordination. Local ethics approval was obtained from the Italian Ministry of Health.

The study met the MSF Ethics review Board (Geneva, Switzerland) approved criteria for studies of routinely collected data and was also approved by the Ethics Advisory Group of the International Union Against Tuberculosis and Lung Disease, Paris, France. Informed consent was not sought from research subjects, as the study was conducted as a retrospective analysis of routine programme data. Anonymity and confidentiality were maintained, and the research subjects were assured the same complement of health services as mandated by the $\mathrm{MoH}$.

Table 1 Characteristics of landings at Augusta harbor (Italy) from Aug 1-Dec 31, 2014

\begin{tabular}{lll}
\hline Variable & TOTAL & $(\%)$ \\
\cline { 2 - 3 } & $\mathrm{n}$ & $(100)$ \\
\hline No. landings & 51 & \\
No. of migrants per landing & & $(47)$ \\
$<200$ & 24 & $(25)$ \\
$201-400$ & 13 & $(22)$ \\
$401-600$ & 11 & $(6)$ \\
$>600$ & 3 & \\
Median & 225 & $(61)$ \\
$\quad$ (IQR) & $(152-414 \cdot 5)$ \\
Time to transfer out ${ }^{\mathrm{a}}$ (hours) & & $(35)$ \\
$<24$ & 31 & $(0)$ \\
$24-48$ & 18 & \\
$49-96$ & 0 & \\
$>96$ & 2 & \\
Median & 12 & \\
$\quad$ (IQR) & $(6-29 \cdot 5)$ \\
Reported no. days spent at sea & & \\
Total Range & $18 \cdot 5-1$ & \\
Median (IQR) & $4(2 \cdot 5-9)$ & \\
\hline
\end{tabular}

aTime between disembarkment and transfer out of the port ${ }^{b}$ Information obtained during patient interviews 
Table 2 Demographic characteristics of rescued sea migrants landed at Augusta harbor (Italy) from Aug 1-Dec 31, 2014

\begin{tabular}{|c|c|c|}
\hline Variable & $n$ & $(\%)$ \\
\hline No. migrants landed & 14,939 & $(100)$ \\
\hline \multicolumn{3}{|l|}{ Age category } \\
\hline Total & 14,939 & $(100)$ \\
\hline Adults ( $\geq 18$ years) & 12,361 & (83) \\
\hline Minors (<18 years) & 2578 & $(17)$ \\
\hline \multicolumn{3}{|l|}{ Adults ( $\geq 18$ years) } \\
\hline Total & 12,361 & $(100)$ \\
\hline Male & 10,824 & (88) \\
\hline Female & 1537 & $(12)$ \\
\hline \multicolumn{3}{|l|}{ Minors $\left(<18\right.$ years) ${ }^{a}$} \\
\hline Total & 2578 & $(100)$ \\
\hline Accompanied & 1929 & $(75)$ \\
\hline Unaccompanied & 649 & $(25)$ \\
\hline
\end{tabular}

${ }^{\mathrm{a}}$ Gender distribution for minors was not always recorded by Immigration Police

\section{Results}

During the study period, OMN performed 51 landings at the Augusta harbor, rescuing a total of 14,939 migrants. Most migrants' boats came from Libya (32 rescue events) and Turkey (15) but others came from Egypt and Syria. Boats from different origins could have been rescued in the same event. In six rescue events (12\%), migrants reported having risked their lives during the sea journey due to a shipwreck and/or incidents during rescue operations.

Table 1 shows details about the landings and time in the port. In $61 \%$ of landings, migrants stayed at the harbor less than $24 \mathrm{~h}$. In only two landings was this period greater than $96 \mathrm{~h}$.

Demographic characteristics of migrants at time of landing are shown in Table 2. The majority of adults were males and $17 \%$ were minors, of whom $25 \%$ were unaccompanied.

Of 14,939 migrants landed at Augusta during the study period, 2593 (17\%) consulted the MSF-MOH clinic and 152 (5\% of clinic patients and $1 \%$ of all migrants landed) were referred to hospital; 19 migrants refused referral.

The largest number of migrants consulting at the clinic came from Syria. Other nationalities are shown in Fig. 2.

Demographic features and the vulnerability profile of sea migrants seen at the clinic overall and stratified by region of origin are reported in Table 3. Migrants were predominantly men between 18 and 30 years old and $24 \%$ presented with vulnerabilities, which include pregnant women, children $\leq 5$ years, elderly persons ( $\geq 60$ years), unaccompanied minors, single parents with children of minor age and persons with disabilities. There were significantly more women, children $\leq 5$ years and older adults ( $>30$ years) in Group 1 (Syrian, Iraqi and Palestinian migrants) than in Group 2 (all other nationalities). Migrants from Group 2 were mainly 6-30 years old. Group 1 presented with significantly more vulnerabilities than Group 2 including being $\leq 5$ years old, $\geq 60$ years old, pregnant and disabled. Unaccompanied minors were the most frequent vulnerability in Group 2.

Thirty-three percent of children $\leq 5$ years had an incomplete or unknown vaccination status.

Table 4 shows the clinical characteristics of the migrants. Of those screened for tuberculosis, $10(<1 \%)$

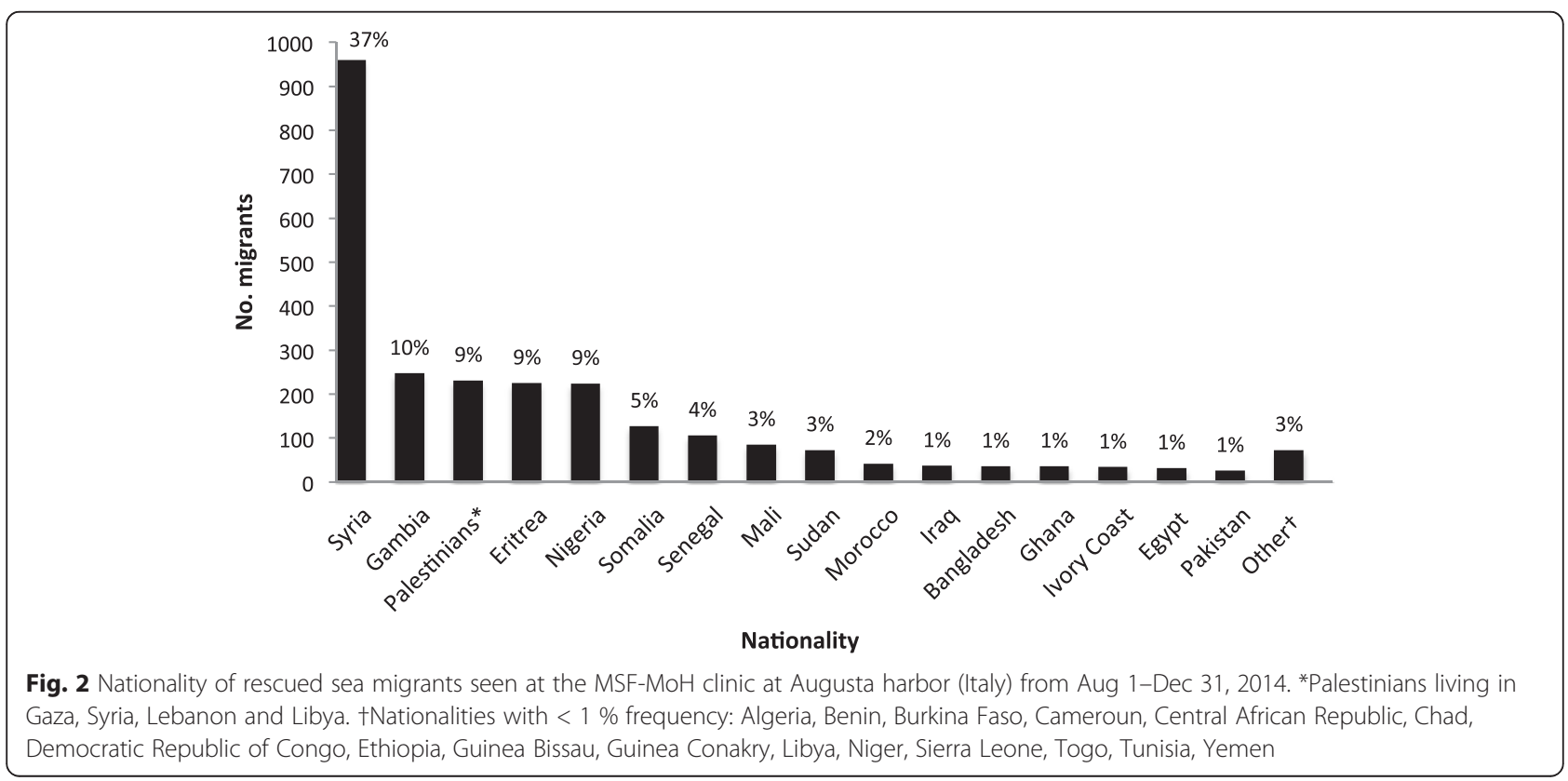


Table 3 Demographic features and vulnerability profile of rescued sea migrants seen at the MSF-MoH clinic at Augusta harbor (Italy) from Aug 1-Dec 31, 2014, stratified by region of origin

\begin{tabular}{|c|c|c|c|c|c|c|c|}
\hline \multirow[t]{2}{*}{ Variable } & \multicolumn{2}{|c|}{ TOTAL } & \multicolumn{2}{|c|}{ Syria, Palestine, Iraq } & \multicolumn{2}{|c|}{ Others $^{a}$} & \multirow[t]{2}{*}{$P$-value } \\
\hline & $\bar{n}$ & (\%) & $\bar{n}$ & (\%) & $\bar{n}$ & $(\%)$ & \\
\hline \multicolumn{8}{|l|}{ Sex } \\
\hline Total & 2593 & $(100)$ & 1227 & $(100)$ & 1366 & $(100)$ & \\
\hline Males & 2101 & $(81)$ & 906 & $(74)$ & 1195 & $(87)$ & $<0.001$ \\
\hline Females & 492 & (19) & 321 & $(26)$ & 171 & (13) & \\
\hline \multicolumn{8}{|l|}{ Age, years } \\
\hline Total & 2593 & $(100)$ & 1227 & $(100)$ & 1366 & $(100)$ & \\
\hline$\leq 5$ & 218 & (8) & 195 & $(16)$ & 23 & $(2)$ & $<0.001$ \\
\hline $6-17$ & 344 & (13) & 120 & $(10)$ & 224 & $(16)$ & $<0.001$ \\
\hline $18-30$ & 1373 & $(53)$ & 444 & $(36)$ & 929 & $(68)$ & $<0.001$ \\
\hline $31-59$ & 589 & $(23)$ & 415 & (34) & 174 & $(13)$ & $<0.001$ \\
\hline$\geq 60$ & 47 & $(2)$ & 46 & (4) & 1 & $(<1)$ & $<0.001$ \\
\hline Not recorded & 22 & (1) & 7 & $(<1)$ & 15 & $(1)$ & \\
\hline \multicolumn{8}{|c|}{ Presence of vulnerability (definitions below) } \\
\hline Total & 2593 & $(100)$ & 1227 & $(100)$ & 1366 & $(100)$ & \\
\hline Yes & 612 & $(24)$ & 332 & $(27)$ & 280 & $(20)$ & $<0.001$ \\
\hline No/Not recorded & 1981 & $(76)$ & 895 & $(73)$ & 1086 & (80) & \\
\hline \multicolumn{8}{|l|}{ Burden of vulnerabilities } \\
\hline Total & $619^{c}$ & $(100)$ & $337^{c}$ & $(100)$ & $282^{c}$ & $(100)$ & \\
\hline$\leq 5$ years old & 218 & $(35)$ & 195 & $(58)$ & 23 & $(8)$ & $<0.001$ \\
\hline Unaccompanied minor & 201 & $(32)$ & 0 & $(<1)$ & 201 & $(71)$ & $<0.001$ \\
\hline Pregnant & 69 & (11) & 42 & $(12)$ & 27 & $(10)$ & $<0.001$ \\
\hline Disabled & 69 & (11) & 48 & (14) & 21 & (7) & $<0.001$ \\
\hline$\geq 60$ years old & 47 & (8) & 46 & $(14)$ & 1 & $(<1)$ & $<0.001$ \\
\hline$S P C M A^{d}$ & 15 & (2) & 6 & (2) & 9 & (3) & \\
\hline
\end{tabular}

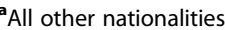

${ }^{\text {b }}$ Significant $P$-values only $(<0.05)$ are shown in the table

${ }^{\circ} 6$ patients presented with two vulnerabilities

${ }^{\mathrm{d}} \mathrm{SPCMA}-$ Single parent with children of minor age

were non-confirmed clinical suspects and one suspect was subsequently confirmed at the hospital. Two migrants reported to have been previously diagnosed with tuberculosis and were already on treatment.

The most frequent presenting conditions involved the respiratory tract, followed by skin and trauma-related conditions.

A significantly higher number of Group 1 migrants consulted because of cardiovascular, endocrinological (diabetes), respiratory, gastrointestinal and gynecoobstetric problems, while skin and neurological conditions (almost exclusively headache) were more frequent in Group 2. We diagnosed 354 scabies cases, $95 \%$ of which belonged to Group 2 (25\% prevalence in Group 2).

Additionally, Group 1 migrants consulted at the clinic for a medical check-up more often than Group 2 migrants.
Overall, most of the study population reported symptoms' onset during migration. However, more migrants from Group 1 reported symptoms' onset before migration as well as since landing as compared to Group 2.

The prevalence of chronic disease was significantly higher in Group 1, including cardiovascular disease and diabetes, which were the most common co-morbidities.

Table 5 shows presenting conditions in detail.

Table 6 shows the number of patients referred to the hospital, their vulnerabilities as well as reasons and outcomes of referral. Of those referred, $20 \%$ were hospitalized. Nearly half of migrants referred to hospital presented with vulnerabilities, the most frequent being pregnancy. The three most common reasons for referral were related to trauma, gyneco-obstetric and respiratory conditions. There were no significant differences 
Table 4 Clinical features of rescued sea migrants seen at the MSF-MoH clinic at Augusta harbor (Italy) from Aug 1-Dec 31, 2014, stratified by region of origin

\begin{tabular}{|c|c|c|c|c|c|c|c|}
\hline \multirow[t]{2}{*}{ Variable } & \multicolumn{2}{|l|}{ TOTAL } & \multicolumn{2}{|c|}{ Syria, Palestine, Iraq } & \multicolumn{2}{|c|}{ Others $^{a}$} & \multirow[t]{2}{*}{$P$-value } \\
\hline & $n$ & $(\%)$ & $n$ & $(\%)$ & $n$ & $(\%)$ & \\
\hline \multicolumn{8}{|l|}{ Outcome of tuberculosis screening } \\
\hline Total & 2593 & $(100)$ & 1227 & $(100)$ & 1366 & $(100)$ & \\
\hline No clinical suspicion & 2573 & (99) & 1225 & (99) & 1348 & (99) & $<0.001$ \\
\hline Clinical suspicion, not confirmed & 10 & $(<1)$ & 1 & $(<1)$ & 9 & $(<1)$ & 0.02 \\
\hline Clinical suspicion, confirmed & 1 & $(<1)$ & 0 & (0) & 1 & $(<1)$ & \\
\hline Previously confirmed and already on therapy & 2 & $(<1)$ & 0 & (0) & 2 & $(<1)$ & \\
\hline Not recorded & 7 & $(<1)$ & 1 & $(<1)$ & 6 & $(<1)$ & \\
\hline \multicolumn{8}{|l|}{ Presenting conditions } \\
\hline Total & $2987^{c}$ & $(100)$ & $1393^{c}$ & (100) & $1594^{c}$ & (100) & \\
\hline Respiratory & 629 & $(21)$ & 320 & (23) & 309 & (19) & 0.02 \\
\hline Dermatological & 585 & $(20)$ & 159 & (11) & 426 & (27) & $<0.001$ \\
\hline Trauma & 344 & $(12)$ & 152 & (11) & 192 & (12) & \\
\hline Gastrointestinal & 299 & $(10)$ & 157 & (11) & 142 & (9) & 0.03 \\
\hline Neurological & 233 & (8) & 94 & (7) & 139 & (9) & 0.05 \\
\hline Medical check-up ${ }^{d}$ & 125 & (4) & 107 & (8) & 18 & (1) & $<0.001$ \\
\hline Dental & 104 & (3) & 48 & (3) & 56 & (4) & \\
\hline Ophthalmological & 98 & (3) & 40 & (3) & 58 & (4) & \\
\hline Urogenital & 79 & (3) & 35 & (3) & 44 & (3) & \\
\hline Cardiovascular incl. hypertension & 53 & $(2)$ & 49 & (4) & 4 & $(<1)$ & $<0.001$ \\
\hline Fever & 52 & $(2)$ & 25 & (2) & 27 & (2) & \\
\hline Gyneco-obstetric & 51 & $(2)$ & 31 & (2) & 20 & (1) & 0.04 \\
\hline Endocrinological & 25 & $(1)$ & 20 & (1) & 5 & $(<1)$ & $<0.001$ \\
\hline Mental-health related & 17 & $(1)$ & 10 & (1) & 7 & $(<1)$ & \\
\hline Other ${ }^{\mathrm{e}}$ & 290 & $(10)$ & 145 & (10) & 145 & (9) & \\
\hline Not recorded & 3 & $(<1)$ & 1 & $(<1)$ & 2 & $(<1)$ & \\
\hline \multicolumn{8}{|l|}{ Symptoms' onset } \\
\hline Total & 2593 & $(100)$ & 1227 & $(100)$ & 1366 & $(100)$ & \\
\hline Before migration & 373 & $(14)$ & 216 & (18) & 157 & (11) & $<0.001$ \\
\hline During migration & 1873 & $(72)$ & 761 & (62) & 1112 & (81) & $<0.001$ \\
\hline Since arrival & 218 & (8) & 140 & (11) & 78 & (6) & $<0.001$ \\
\hline Does not apply ${ }^{f}$ & 127 & (5) & 108 & (9) & 19 & (1) & $<0.001$ \\
\hline Not recorded & 2 & $(<1)$ & 2 & $(<1)$ & 0 & (0) & \\
\hline \multicolumn{8}{|l|}{ Presence of chronic disease (definitions below) } \\
\hline Total & 2593 & $(100)$ & 1227 & $(100)$ & 1366 & $(100)$ & \\
\hline Yes & 291 & $(11)$ & 232 & (19) & 59 & (4) & $<0.001$ \\
\hline No/Not recorded & 2302 & (89) & 995 & (81) & 1307 & (96) & \\
\hline \multicolumn{8}{|l|}{ Burden of chronic disease } \\
\hline Total & $313^{9}$ & $(100)$ & $254^{9}$ & $(100)$ & $59^{9}$ & (100) & \\
\hline Cardiovascular & 86 & $(27)$ & 81 & (32) & 5 & (8) & $<0.001$ \\
\hline Diabetes & 53 & $(17)$ & 48 & (19) & 5 & (8) & 0.05 \\
\hline Orthopedic & 33 & $(11)$ & 27 & (11) & 6 & (10) & \\
\hline Gastrointestinal & 30 & $(10)$ & 21 & (8) & 9 & (15) & \\
\hline
\end{tabular}


Table 4 Clinical features of rescued sea migrants seen at the MSF-MoH clinic at Augusta harbor (Italy) from Aug 1-Dec 31, 2014, stratified by region of origin (Continued)

\begin{tabular}{|c|c|c|c|c|c|c|c|}
\hline Chronic lung disease & 18 & (6) & 14 & (6) & 4 & (7) & \\
\hline Neurological & 15 & (5) & 12 & (5) & 3 & (5) & \\
\hline Urogenital & 10 & (3) & 5 & (2) & 5 & (8) & 0.01 \\
\hline Dermatological & 3 & (1) & 3 & (1) & 0 & (0) & \\
\hline Endocrinological $^{h}$ & 3 & (1) & 3 & (1) & 0 & (0) & \\
\hline Other ${ }^{i}$ & 62 & $(20)$ & 40 & (16) & 22 & (37) & $<0.001$ \\
\hline
\end{tabular}

${ }^{\mathrm{a} A l l}$ other nationalities

${ }^{\mathrm{b}}$ Significant $P$-values only $(<0.05)$ are shown in the table

${ }^{C}$ For each patient we could record a maximum of two clinical conditions (16\% of patients seen)

${ }^{\mathrm{d} P a t i e n t s ~ c o n s u l t i n g ~ m o s t l y ~ f o r ~ b l o o d ~ p r e s s u r e, ~ b l o o d ~ s u g a r ~ o r ~ t e m p e r a t u r e ~ c h e c k ~}$

'Most common: fatigue, discomfort, pain (myalgia, arthralgia, skeletal pain, etc.), otitis/otalgia, abscess, dizziness, dehydration, agitation and panic attack, anemia,

rheumatic disease, need for chronic medications, loss of eyeglasses, malnutrition, palpitation, hearing loss

${ }^{f}$ For patients coming for check-up

${ }^{9} 22$ patients (all from the group "Syria, Palestine, Iraq") presented with 2 chronic diseases, mainly cardiovascular disease and diabetes

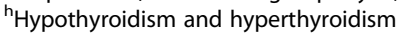

'Most common: congenital diseases (e.g. anemia), autoimmune diseases, disabilities, mental illnesses, nephrolithiasis, renal failure, chronic ear or eye disease,

prostatic hypertrophy

between the two groups in terms of frequency, outcomes and reasons of referral.

\section{Discussion}

This is the first study assessing the demographic and clinical features of sea migrants at the time of arrival to Europe. This information has never been more important, considering the challenge many European countries are currently facing of ensuring quality medical care to newly-arrived migrants.
A major finding was that there were two migrant groups that differed significantly in terms of demographic and clinical characteristics, as well as patterns of vulnerability. Migrants from the Near East (Syrians, Iraqis and Palestinians) included a large proportion of small children, pregnant women, elderly and disabled people. Among this group there was more acute and chronic vascular disease, diabetes, and health-seeking behavior. The other group included mostly African migrants of young age. Among them there were more unaccompanied minors and patients with skin diseases, including scabies.

Table 5 Most common presenting conditions at the MSF-MoH clinic at Augusta harbor (Italy) from Aug 1-Dec 31, 2014, by category

\begin{tabular}{ll}
\hline Category & Diagnoses \\
\hline Respiratory & Asthma, chronic obstructive lung disease, upper and lower respiratory tract infection \\
$\begin{array}{l}\text { Dermatological } \\
\text { Trauma }\end{array}$ & $\begin{array}{l}\text { Burn, head and pubic lice, psoriasis, skin infection (including scabies), skin rash (including allergy), wound } \\
\text { Contusion, fracture, joint dislocation, pain and/or functional disability following physical trauma or due } \\
\text { to presence of foreign body }\end{array}$ \\
Gastrointestinal & Abdominal and epigastric pain, gastroenteritis, hemorrhoids, nausea, perianal abscess and fissure \\
Cheurological & Headache (almost exclusively), known brain tumor, seizure \\
Dental & Blood pressure, blood sugar or temperature check \\
Ophthalmological & Dental abscess, tooth pain \\
Urogenital & Cataract, conjunctivitis, decreased sight \\
Cardiovascular including hypertension & Nephrolithiasis, urinary tract and genital infections \\
Fever & Chest pain, collapse, hypertensive crisis, hypotension \\
Gyneco-obstetrical & Fever with no infection signs \\
Abdominal pain in pregnant woman, absence of fetal movements, suspected pregnancy, vaginal \\
bndocrinological & bleeding in pregnant woman \\
Mental-health related & Diabetes (almost exclusively), hypoglycemia \\
Other & Depression, schizophrenia \\
& Abscess, agitation and panic attack, anemia, dehydration, discomfort (non-specific), dizziness, fatigue, \\
hearing loss, loss of eyeglasses, malnutrition, need for drug supply, otitis/otalgia, pain (myalgia, arthralgia, \\
rachialgia, etc.), palpitations, rheumatic disease
\end{tabular}


Table 6 Outcomes and reasons for hospital referrals from Augusta harbor (Italy) from Aug 1-Dec 31, 2014

\begin{tabular}{|c|c|c|}
\hline Variable & $\mathrm{n}$ & $(\%)$ \\
\hline No. patients referred & $152^{\mathrm{a}}$ & $(100)$ \\
\hline \multicolumn{3}{|l|}{ Presence of vulnerability (definitions below) } \\
\hline Yes & 70 & $(46)$ \\
\hline No/Not recorded & 82 & $(54)$ \\
\hline \multicolumn{3}{|l|}{ Burden of vulnerabilities } \\
\hline Total & 70 & $(100)$ \\
\hline Pregnant & 37 & $(53)$ \\
\hline$\leq 5$ years & 10 & $(14)$ \\
\hline Unaccompanied minor & 9 & $(13)$ \\
\hline Disabled & 8 & $(11)$ \\
\hline$\geq 60$ years & 5 & (7) \\
\hline SPCMA ${ }^{b}$ & 1 & (1) \\
\hline \multicolumn{3}{|l|}{ Reasons for referral } \\
\hline Total & 152 & $(100)$ \\
\hline Trauma & 35 & $(23)$ \\
\hline Gyneco-obstetrical & 33 & $(22)$ \\
\hline Respiratory & 20 & $(13)$ \\
\hline Cardiovascular incl. hypertension & 11 & (7) \\
\hline Gastrointestinal & 10 & (7) \\
\hline Neurological & 7 & (5) \\
\hline Dermatological & 6 & $(4)$ \\
\hline Surgical & 5 & (3) \\
\hline Fever & 5 & (3) \\
\hline Urogenital & 4 & (3) \\
\hline Medical check-up & 3 & $(2)$ \\
\hline Endocrinological & 2 & $(1)$ \\
\hline Dental & 1 & $(<1)$ \\
\hline Mental-health related & 1 & $(<1)$ \\
\hline Other ${ }^{c}$ & 9 & (6) \\
\hline \multicolumn{3}{|l|}{ Outcome of referral } \\
\hline Total & 152 & $(100)$ \\
\hline Discharged from the Emergency Room & 110 & $(72)$ \\
\hline Hospitalized & 31 & $(20)$ \\
\hline Not recorded & 9 & (6) \\
\hline Left before diagnosis/treatment completed & 2 & $(2)$ \\
\hline
\end{tabular}

${ }^{a} 12$ Patients were referred directly to hospital from triage and did not consult the MSF-MoH clinic, therefore hospitalization rate for clinic patients was $5 \%$ ( $1 \%$ overall)

${ }^{b}$ SPCMA-Single parent with children of minor age

'Collapse, dehydration, otitis, hypothermia, malnutrition

However, some diseases of the two groups were similar, with the most common being respiratory, dermatological and gastrointestinal conditions, as well as trauma. We suggest these are likely associated with the dangerous journey. Migrants travelled for days on unseaworthy and overcrowded boats, where hygiene conditions were poor, the climate was cold and wet, water and food were scarce and often contaminated [3, 5, 23]. Injuries could be sustained while getting onto the migrant boat or during rescue operations. Some suffered immersion in the sea. Prior to the sea crossing, many had undertaken long journeys across the desert followed by difficult living conditions in Libya, with repeated violence and exploitation. This contributed to the burden of trauma-related conditions [24].

A positive feature of this project was that the MSF$\mathrm{MoH}$ clinic appeared to relieve local hospital facilities of some of the burden of care. Only $5 \%$ of clinic patients and $1 \%$ of all landed migrants were sent to hospital. There was efficient cooperation between MSF and $\mathrm{MoH}$ clinical staff and good relations with the local hospitals. As a result of the collaboration, $\mathrm{MoH}$ took over medical activities at the Augusta harbor in January 2015.

Like ours, earlier studies showed that African migrants were young men and had respiratory and gastrointestinal morbidities as well as traumatic injuries [12-14, 17].

Among all studies, pregnancy-associated conditions were the most common reasons for hospital referral among women $[12,13,15,16]$.

Previous studies of sea migrants did not include the presence of large numbers of migrants from Near Eastern, war-torn regions, who often suffer from chronic diseases and who have a higher and different burden of vulnerabilities. However, our findings are supported by more recent studies conducted with Syrian refugees in Jordan and Lebanon, which focused on the burden of noncommunicable diseases [25, 26].

A number of European studies have focused on communicable diseases in migrants with contradictory findings [14, 27-29]. Our study showed a low burden of infectious diseases of public health significance. There were no suspected cases of Ebola among migrants from Africa, as would be expected following a journey through the Sahara desert that was much longer than the incubation period of the virus.

We note that this study was a snap shot of migrants at a particular time and place. Since then, the migration routes have been changing and further assessments of migrants' health in different contexts will be required to provide adequate medical care.

There are a number of policy implications from this study: 1) It is important to have adequate and accessible medical services at landings to provide immediate care to newly-arrived migrants. They can relieve the burden on local health care facilities and coordinate referrals; 2) Medical care needs to be organized to manage both acute and chronic diseases, given the different profiles of migrants arriving; 3) Care for migrants should be sensitive to screen for and manage vulnerabilities. Vaccination status of children should be systematically assessed and 
vaccines readily available; 4) Adequate training should be offered to health professionals dealing with migrants' health, since this requires not only medical and organizational skills, but also ethical and legal expertise, as well as cultural sensitivity; 5) Comprehensive and accurate data collection of migrants' health needs should be established to properly inform relevant authorities in Europe.

The strengths of this study include a large sample size that was representative of the sea migrants landed during this time period in Italy in terms of demographics and countries of origin. Data collection and entry were validated through cross-checks. The study adhered to the STROBE guidelines [30].

\section{Limitations}

There were some limitations in this study. Although it provides useful insights into migrants' health care, the relatively small study population and narrow time of the intervention could not capture the full picture of the migration issue in all its medical and public health implications. The clinic was temporary and diagnostic testing was very limited, hence the lack of disease specificity. The rapid turnover of migrants limited follow-up of referred patients and prevented assessment of mental health status, which would be important given the traumatic journey. Finally, the study population mostly represented migrants who were actively seeking medical attention, which may be source of selection bias.

\section{Conclusions}

This study shows that there were different profiles of migrants landing in Southern Italy during 2014, having diverse medical requirements. Providing adequate initial medical care to them can address humanitarian obligations and provide support to local medical facilities. These services should be part of the European Union's response to the migrant crisis. Systematic data collection in similar contexts is needed to improve knowledge and training of health care professionals, as well as the level of care for migrants.

\section{Abbreviations \\ CESIRA: Coscienza, Emorragia, Shock, Insufficienza respiratoria, Rottura ossea, Altro; CRI: Croce Rossa Italiana (Italian Red Cross); MoH: Ministry of Health; MSF: Médecins sans frontières; NGO: Non-Governmental Organization; OMN: Operation Mare Nostrum; SPCMA: Single Parent with Children of Minor age; STROBE: STrengthening the Reporting of OBservational studies in Epidemiology.}

\section{Competing interests}

The authors declare that they have no competing interests.

\section{Authors' contributions}

AT collected, cross-checked and elaborated the data, designed the study, interpreted the results and wrote the manuscript. TR gave a significant contribution in designing the study, interpreting the results and writing the manuscript. KT and PO contributed to the data management, the interpretation of the results and the writing up of the manuscript. TD helped create the databases and critically reviewed the manuscript. CM and SD were responsible for the field project and data collection; they also contributed to data interpretation and critically revised the paper. FB gave consent for data utilization and critically revised the manuscript. All authors read and approved the final manuscript.

\section{Authors' information}

AT worked as a MSF clinician at the Augusta project from August to December 2014. CM was the project coordinator and SD the Head of MSF Italian Mission. All of them contributed to establish, run and finally hand over the project to MoH. TD, from the Operational Research Unit Luxemburg, helped create the database that was used for this study, and encouraged the publication of the data from the project. TR, KK and PO contributed to the creation of the study in the context of the SORT IT Program (explained below). FB was the MoH counterpart of the Augusta project and provided us with all necessary institutional approvals.

\section{Acknowledgements}

This research was conducted through the Structured Operational Research and Training Initiative (SORT IT), a global partnership led by the Special Programme for Research and Training in Tropical Diseases at the World Health Organization (WHO/TDR). The model is based on a course developed jointly by the International Union Against Tuberculosis and Lung Disease (The Union) and Medécins sans Frontières. The specific SORT IT programme which resulted in this publication was jointly developed and implemented by: the Operational Research Unit (LUXOR), Médecins Sans Frontières, Brussels Operational Center, Luxembourg; the Centre for Operational Research, The Union, Paris, France; the Centre for International Health, University of Bergen, Norway; the Institute of Tropical Medicine, Antwerp, Belgium; and Partners in Health, USA.

\section{Funding}

This study was part of a MSF project utilizing existing program data; no additional funding was required.

The program SORT IT was funded by The Union, MSF, and the Department for International Development (DFID), UK. The funders had no role in study design, data collection and analysis, decision to publish, or preparation of the manuscript. La Fondation Veuve Emile Metz-Tesch, Luxembourg also supported open access publication costs.

\section{Open access statement}

In accordance with WHO's open-access publication policy for all work funded by WHO or authored/co-authored by WHO staff members, the WHO retains the copyright of this publication through a Creative Commons Attribution IGO licence (http://creativecommons.org/licenses/by/3.0/igo/legalcode) which permits unrestricted use, distribution and reproduction in any medium provided the original work is properly cited.

\section{Author details}

${ }^{1}$ Medici Senza Frontiere Italia, Via Magenta 5, Roma 00185, Italy. ${ }^{2}$ FCFP, Médecins Sans Frontières Bruxelles, Operational Research Unit Luxembourg, 68 rue de Gasperich L-1617, Luxembourg City, Luxembourg. International Union Against Tuberculosis and Lung Disease (IUATLD), Ministry of Health \& Child Care, AIDS \& TB Department, Cnr 5th Street \& Livingstone Avenue, Harare, Zimbabwe. ${ }^{4}$ Médecins Sans Frontières Bruxelles, Operational Centre Brussels, Medical Department, Operational Research Unit Luxembourg, 68 rue de Gasperich L-1617, Luxembourg City, Luxembourg. ${ }^{5}$ Academic Model Providing Access to Healthcare, P.O. Box 4606, Eldoret 30100, Kenya. ${ }^{6}$ Assessorato Salute Regione Sicilia (Local Ministry of Health), Piazza Ottavio Ziino 24, Palermo 90145, Italy.

Received: 4 February 2016 Accepted: 19 April 2016 Published online: 15 June 2016

\section{References}

1. Refugees/Migrants Emergency Response - Mediterranean. United Nations High Commissioner for Refugees. 2015. http://data.unhcr.org/ mediterranean/regional.php. Accessed 29 Nov 2015.

2. Sea arrivals to Italy. United Nations High Commissioner for Refugees. 2014. http://www.unhcr.it/risorse/statistiche/sea-arrivals-to-italy. Accessed 27 Nov 2015. 
3. Lives adrift. Refugees and migrants in peril in the Central Mediterranean Amnesty International. London. 2014. https://www.amnesty.org/en/ documents/EUR05/006/2014/en/. Accessed 27 Nov 2015.

4. Migration trends \& patterns of Syrian asylum seekers travelling to the European Union. REACH Resource Centre. Geneva. 2015. http://data.unher. org/mediterranean/download.php?id=125. Accessed 27 Nov 2015.

5. Fatal journeys - Tracking Lives Lost during Migration. Chapters 3 and 4. Brian T, Laczko F, editors. International Organization for Migration. Geneva. 2014. https://publications.iom.int/system/files/pdf/fataljourneys_ countingtheuncounted.pdf. Accessed 27 Nov 2015.

6. Day $M$. The most lethal route in the world: 3,419 migrants died crossing Mediterranean from Africa to Europe this year. The Independent. 2014 http://www.independent.co.uk/news/world/europe/the-most-lethal-route-inthe-world-3419-migrants-died-crossing-mediterranean-this-year-9916436. html. Accessed 29 Nov 2015

7. Mare Nostrum Operation. http://www.marina.difesa.it/EN/operations/Pagine/ MareNostrum.aspx. Accessed 29 Nov 2015.

8. UNHCR Presentation at the $12^{\text {th }}$ Mediterranean Conference of Red Cross and Red Crescent Societies. San Marino, May 27 ${ }^{\text {th }} 2015$. http://www. rcrcmediterraneanconference.org/detail.asp?c=2\&p=0\&id=1108. Accessed 19 Dec 2015.

9. Immigration data 2014/2015, Italy. Italian Ministry of Intern. 2015. http:// www.magistraturademocratica.it/mdem/articolo.php?id=2339. Accessed 27 Nov 2015

10. Italy Releases New Data on Migrant Arrivals through End of November. International Organization for Migration. 2014. http://missingmigrants.iom. int/italy-releases-new-data-migrant-arrivals-through-end-november. Accessed 29 Nov 2015.

11. Ebola e tbs sbarcano con gli immigrati. II Giornale. 2014. http://www. ilgiornale.it/news/interni/ebola-e-tbc-sbarcano-immigrati-1011595.html. Accessed 29 Nov 2015.

12. Padovese $\mathrm{V}$, Egidi $A M$, Melillo Fenech $T$, et al. Migration and determinants of health: clinical epidemiological characteristics of migrants in Malta (2010-11). J Public Health. 2013;36:368-74.

13. Prestileo T, Cassarà G, Di Lorenzo F, Sanfilippo A, Renato E, Orlando G. Salute e malattie infettive nella popolazione migrante: I'esperienza della 'Coorte di Lampedusa 2011'. Le Infez Med. 2013;1:21-8.

14. Napoli C, Riccardo F, Declich S, et al. an early warning system based on syndromic surveillance to detect potential health emergencies among migrants: results of a two-year experience in Italy. Int J Environ Res Public Health. 2014;11:8529-41.

15. Firenze A, Restivo V, Bonanno V, Aleo N, Pace S, Laura MG. Health status of immigrants arrived to Italian coast. Epidemiol Prev. 2014;38:78-82.

16. Pasta L, Marchese G, Farinella EM. The health of people who cross the Strait of Sicily on a floating wreck. Epidemiol Prev. 2011;35:167.

17. Affronti M, Affronti A, Pagano S, et al. The health of irregular and illegal immigrants: Analysis of day-hospital admissions in a department of migration medicine. Intern Emerg Med. 2013;8:561-6.

18. Calderón-Larrañaga A, Gimeno-Feliu L, Macipe-Costa R, Poblador-Plou B, Bordonaba-Bosque D, Prados-Torres A. Primary care utilisation patterns among an urban immigrant population in the Spanish National Health System. BMC Public Health. 2011;11:432.

19. Brzoska P, Ellert U, Kimil A, et al. Reviewing the topic of migration and health as a new national health target for Germany. Int J Public Health. 2015:60:13-20.

20. Galanis P, Sourtzi P, Bellali T, et al. Public health services knowledge and utilization among immigrants in Greece: a cross-sectional study. BMC Health Serv Res. 2013;13:350.

21. Piano di Contingenza Sanitario Regionale Migranti. Gazzetta Ufficiale della Regione Italiana. Italian Ministry of Health. Palermo, 3 Oct 2014. http://www. gurs.regione.sicilia.it/Gazzette/g14-42o/g14-42o.pdf. Accessed 29 Nov 2015.

22. Médecins sans Frontières. Clinical guidelines. Paris. 2013. http://refbooks.msf. org/msf_docs/en/clinical_guide/cg_en.pdf. Accessed 29 Nov. 2015.

23. Birga V, Bierwirth C, Bjerregaard A, et al. International Migration, Health and Human Rights. Geneva. 2013 https://publications.iom.int/books/ international-migration-health-and-human-rights. Accessed 29 Nov 2015.

24. Libya: Whipped, Beaten, and Hung from Trees. Detained Migrants, Asylum Seekers Describe Torture, Other Abuse in Detention. Human Rights Watch. 2014. https://www.hrw.org/news/2014/06/22/libya-whipped-beaten-andhung-trees. Accessed 29 Nov 2015.
25. Doocy S, Lyles E, Roberton T, Akhu-Zaheya L, Oweis A, Burnham G. Prevalence and care-seeking for chronic diseases among Syrian refugees in Jordan. BMC Public Health. 2015;15:1097.

26. Strong J, Varady C, Chahda N, Doocy S, Burnham G. Health status and health needs of older refugees from Syria in Lebanon. Confl Health. 2015;9:12.

27. Assessing the burden of key infectious diseases affecting migrant populations in the EU/EEA. European Centre for Disease Prevention and Control. Stockholm. 2014. doi:10.2900/28792.

28. Riccardo F, Dente MG, Kärki T, et al. Towards a European Framework to Monitor Infectious Diseases among Migrant Populations: Design and Applicability. Int J Environ Res Public Health. 2015;12:11640-61.

29. Kärki T, Napoli C, Riccardo F, et al. Screening for infectious diseases among newly arrived migrants in EU/EEA countries-Varying practices but consensus on the utility of screening. Int J Environ Res Public Health. 2014;11:11004-14.

30. von Elm E, Altman DG, Egger M, Pocock SJ, Gøtzsche PC, Vandenbroucke JP. The Strengthening the Reporting of Observational Studies in Epidemiology (STROBE) statement: guidelines for reporting observational studies. J Clin Epidemiol. 2008;61:344-9.

\section{Submit your next manuscript to BioMed Central and we will help you at every step:}

- We accept pre-submission inquiries

- Our selector tool helps you to find the most relevant journal

- We provide round the clock customer support

- Convenient online submission

- Thorough peer review

- Inclusion in PubMed and all major indexing services

- Maximum visibility for your research

Submit your manuscript at www.biomedcentral.com/submit
Biomed Central 